\title{
Making managerial policy in the neoliberal moment
}

By the 1990s, a consensus was emerging in British medicine about the need for new instruments of professional management and clinical regulation. In the four decades after the 1950s, professional, political, and public anxieties about standards of medical practice had grown inexorably. Critiques of variations and evidence in medical care had joined with concerns about cost and professional accountability to produce a 'crisis' over quality. Locally, some practitioners responded by intensifying projects for structured care, creating more precise protocols and undertaking institutional audits. Nationally, elite professional bodies and leading specialists produced guidelines to inform local developments, and sought to establish national datasets and audit systems. Through these changes, previously informal measures regulating clinical activity became explicit, and the rhythms and content of care became subject to new forms of structure and review.

The Conservative governments of the 1980s and 1990s had also become interested in guidelines and medical audit. Motivated by historic drives to control costs and increase efficiency in the health service - as well as by neoliberal critiques of state and economy - the Thatcher and Major administrations substantially remade the dynamics of the NHS. Inspired by the novel concept of internal markets in public services, extensive reforms converted health authorities from planning and management bodies into state-funded healthcare purchasers, and transformed hospitals and community care agencies into trusts that secured finance through procuring contracts from purchasing bodies. ${ }^{1}$ In primary care, larger general practices were encouraged to operate as purchasers of certain hospital services (such as outpatient care), and new GP contracts introduced enhanced pay-for-performance elements. ${ }^{2}$ Guidelines and medical audit were to play important roles in the new system. Although remaining under the control of professional 
bodies, these instruments would enhance professional accountability and provide standards against which care could be measured before payments were made. The earliest moves in this direction were made in relation to chronic disease, with diabetes a prominent target. Long-term conditions were costly problems, and better management promised to improve prevention of expensive sequelae. Furthermore, as diseases that crossed institutional lines, intervention enabled governments to tackle the thorny GP-hospital divide. Measures to confront these problems were included in the 1990 GP contract (and subsequent revisions), as well as forming the basis of reviews into clinical standards in the mid-1990s. By the late 1990s, diabetes had become one of the first conditions to be subject to a National Service Framework (NSF).

Given the contrast between professional and government political projects, this chapter explores how management of professional labour became government policy during the 1980s and 1990s. Despite disparities in aims, specialists and elite professional bodies found common ground with government and state agencies over the production of guidelines and audit structures. All parties saw benefits in co-operation and actively sought collaboration. Reliant upon medical professionals to construct new tools, government often acted through financial support for local programmes, supplemented by assistance for projects undertaken in national bodies. These efforts, moreover, were cultivated by key specialists and professional organisations, who sought resources and authority to develop new instruments. The creation of managerial policy, in other words, was co-constructed. Furthermore, this chapter stresses that elite bodies and leading specialists were crucial to initiating and connecting local, national, and international efforts to manage diabetes and its doctors. Personnel overlaps ensured strong consensus over the nature of reform across different scales of policy creation and service delivery. It was through mobile and influential figures, then, that government and professional projects were aligned enough for management of professional labour to become policy. Of course, the actual and intended effects of policy could be subverted by either government or profession, and the efforts of both sides could be mediated in practice. Nonetheless, their co-operation secured the basis for managerial policy and set the stage for more extensive future reform.

Finally, this chapter suggests that the policy networks surrounding diabetes noted in Chapter 4 were essential in establishing the condition at the forefront of new managerial policies. As a costly, cross-sectoral problem, diabetes - and chronic disease more broadly - provided an 
important entry point for promoting managerial technologies in the health service. In part, such intervention was facilitated by the institutional and technological groundwork laid in earlier decades. However, governments were also concerned about the possible financial and political costs of intervening in certain areas, meaning that stateprofessional relations were not always smooth. It was here that the strength of the diabetes policy community became important. Through a vocal lay-professional organisation, interested civil servants, persuasive specialist advocates, and international pressure (especially from the WHO), diabetes was established as an important subject for novel managerial technologies. Diabetes thus provides a lens through which to view managerial policy, not only because of how it was conceived as a possible model for change, but also because of the ways in which it became an object of political interest.

\section{Managing British medicine before 1979}

The 1980s and early 1990s were a period of radical innovation in British health policy. ${ }^{3}$ During these years, Conservative administrations significantly altered the institutional configuration and dynamics of British healthcare, transforming the role of health authorities and central government in delivering health services. Neoliberal analyses of professionals, bureaucracy, state, and economy provided a broad underpinning for much reform. However, the Thatcher and Major governments were also motivated by a long-held desire of the British state to control NHS costs, and later initiatives built upon developments that took place before the 1980s.

Parliament and the Treasury had placed constant pressure on NHS budgets since 1948. Initial hopes that expenditure would decline as national health improved were dashed very quickly. Governments tried numerous strategies over the post-war period to control costs, ranging from the introduction of charges (most notably for prescriptions in the 1950s) to the application of innovative budgetary rules, such as the Labour government's cash-limited budgeting of the mid-1970s. ${ }^{4}$ Maintaining satisfactory levels of provision, however, required considerable resources, and efficiency savings could stretch only so far.

Civil servants, politicians, think-tanks, and professional advisory bodies had noted the problematic connection between resource use and clinical decision-making soon after the creation of the NHS. However, the Ministry (and later Department) of Health felt unable to 
directly intervene in clinical judgement, given the poor quality of information available and the strength of anxiety that interference would generate backlash from both the public and the profession alike. ${ }^{5}$ Instead, until the 1980s, state bodies and central professional advisory agencies sought to confront the issue of costs through improved service monitoring systems, and by encouraging clinicians to use institutional and comparative data to reform their own practices. These efforts began in the early 1950s. During these years, the CHSC sponsored the King's Fund and Nuffield Provincial Hospitals Trust to research alternative accounting systems within hospitals. New schemes linked costs with activity, enabling administrators to compare expenditure longitudinally and between institutions and to highlight possible areas for efficiency. Although they were trialled in various hospitals, implementation costs and administrative concerns about clinician interest resulted in less effective compromises being adopted. ${ }^{6}$ Likewise, efforts to control prescribing costs in the 1950s were predicated upon exhortations about 'excessive prescribing' from the Chief Medical Officer in the Ministry of Health and on statistical analyses sent to GPs of their prescribing costs relative to other practitioners. ${ }^{7}$ It was hoped that GPs would reflect on this information and alter their practices if their supposed deviations from common practice resulted in greater expenditure. The increasing costs of the drug bill indicate that such efforts did not achieve their ultimate objectives. ${ }^{8}$

Similar, if more complex, techniques were applied to the problem of clinically driven costs in the 1960s and 1970s. The Ministry of Health's Hospital Plan, launched in 1962, loosely practised budget planning, linking finance to specified outcomes and producing national bed norms per population. ${ }^{9}$ The Plan itself emerged during a decade within which programme planning, budgeting, and review became more common within Whitehall. ${ }^{10}$ Similarly, during the mid- to late 1960 s the Ministry developed a new hospital information system, in which hospitals attached data sheets to each inpatient case file and sent 'returns' to RHBs for statistical analysis. Although it experienced problems of timeliness and accuracy, through this Hospital Activity Analysis 'for the first time it was possible, in theory, for consultants to relate the use of resources to the characteristics of their patients, their diagnoses, and their treatments.' This new data system was entangled with attempts to incorporate clinicians into management structures, such as Cogwheel divisions or the consensus management groups upon which the 1974 NHS reforms were built. Improved monitoring was also 
needed for Labour's turn to priority-setting and planning in the $1970 \mathrm{~s}^{12}$ Information provision and professional self-management sat at the heart of all such activities, with the hope that self-regulation could bring expenditure under greater control.

Neoliberalism, welfare reform, and the management of British medicine

Political concerns about the relationship between clinical decisionmaking and resource use continued after the election of Margaret Thatcher in 1979. Comments from parliamentary select committees during this period indicate that traditional fiscal conservatives and social democrats were united in a desire to, at the very least, map the effects of NHS expenditure - in short, to better understand what the benefits of state expenditure actually were. ${ }^{13}$ However, the connection between professional autonomy and NHS expenditure disturbed successive Conservative administrations for reasons beyond traditional anxieties about public finances. Rather, the Party, and leading ministers, were increasingly influenced by neoliberal critiques of self-interested welfare professionals and state over-extension during the 1980s and 1990s. Such thinking shaped government policy, with reform packages inflected by debates about the efficiency of markets and the political importance of enterprise. In terms of the NHS, Conservative administrations developed attempts to promote professional self-management, but connected health policy with a broader remaking of the state. Before examining how these critiques informed health policy after 1979 , it is worth returning to the often vexed question of 'neoliberalism', which we began to explore in Chapter $4 .{ }^{14}$

Although not gaining political currency in Britain for decades, neoliberal critiques first emerged in the 1930 s and 1940 s. ${ }^{15}$ At this time, a small number of economists and political philosophers reacted against what they saw as a crisis of liberalism, in which liberal governments created mechanisms for securing individual freedom (from disease or old age) by collectivising social risks. ${ }^{16}$ Faced with post-war planning and destructive totalitarian regimes, neoliberal theorists sought to rethink liberalism, and recast state interventions in social and economic realms as a risk to the individualised self-determination supposedly at the heart of Western civilisation. ${ }^{17}$ Markets in such analyses represented not only the most efficient means for allocating resources, but also a political bulwark. Economic freedom and competition provided 
the basis for all liberty, and state encroachment here would inevitably result in political authoritarianism. ${ }^{18}$ Moreover, in simple economic terms, thinkers such as Friedrich Hayek suggested that central planning and bureaucracy stunted creativity and spontaneous order, and crucially lacked the means to create and process all the information required for efficient production and consumption. ${ }^{19}$ Prices, by contrast, provided the signal for individuals to make their own choices, and inequality of outcome rewarded people who made the right decisions (or incentivised improvement, if they made the wrong ones). ${ }^{20}$ In this sense, the role of the state was to establish the infrastructure for economic competition between private agents, and to provide limited, non-redistributive, social welfare (i.e. that which did not interfere with the rewards and pricing central to market competition). ${ }^{21}$ As Foucault suggests, for early neoliberal theorists the market and its governance requirements thus constituted the raison d'etre and limit of the state, but markets were not to be laissez-faire. ${ }^{22}$ Unlike proponents of classical liberalism, neoliberal thinkers did not see the market as a natural phenomenon. From their perspective, states would be required to establish frameworks for economic activity, and to constantly monitor and intervene to guarantee competition (for instance, to prevent unfair practices) and manage the environment required for enterprise (e.g. by supporting education). This work would be ongoing as capital consistently produced newer and newer circumstances and arrangements. ${ }^{23}$

Over the post-war decades, neoliberal critiques of state and economy were promoted by international networks of economists, political scientists and philosophers through think-tanks, business organisations, journalism, and academia. ${ }^{24}$ Core ideas and languages changed over this period. At the height of the Cold War, figureheads like the American economist Milton Friedman amplified a rhetoric of laissez-faire and economic primacy, even if this looked very different from eighteenthand nineteenth-century variants. ${ }^{25}$ Likewise, post-war neoliberal thinkers moved economic analyses into new realms. ${ }^{26}$ Paramount in the British case were critiques of areas previously seen as distinct from private enterprise: state bureaucracy and professionally delivered welfare. According to such analyses, state employees and welfare professionals were not altruistic or service-oriented so much as self-interested and unaccountable. ${ }^{27}$ Slowly, neoliberal critique concerning the efficiency of markets, the moral and political importance of competition, and the regulative role and limits of the state seeped into British 
political discourse, and Conservative politicians in particular engaged earnestly with these ideas from the 1970 s onwards. ${ }^{28}$ Arguments about the degenerative effects of the state on British life were central to crisis narratives around supposed political consensus, providing the platform for the 1979 Conservative election victory. ${ }^{29}$

Into the 1980s and 1990s, neoliberalism was but one ideological framework within which the Conservative Party developed its thinking. ${ }^{30}$ All government policy was subject to the dynamics of British politics, from the electorate's attachment to redistributive welfare (embodied in the NHS) to ministerial individuality and constraints imposed by previous policy decisions. ${ }^{31}$ Indeed, a leaked government think-tank paper in 1982 proposed remaking health services on an insurance basis. It provoked such political backlash that future policy groups consistently dismissed the idea, and the Prime Minister felt it necessary to insist that the NHS was 'safe in our hands. ${ }^{32}$ Nonetheless, over the 1980s and 1990s, neoliberalism as a rationality for organising the state slowly gained influence, even if providing only a set of analytical principles rather than a dominant grand plan. ${ }^{33}$ Thus the Conservative governments of 1979-97 reformed union rights and social security, arguing that such changes would enhance labour market functionality and restore the political bulwark of market choice and democratic decision-making. ${ }^{34}$ They denationalised firms and industries to reduce public ownership and promote market competition, establishing the state in a monitoring and regulatory role. ${ }^{35}$ Such ideas even entered into the provision of welfare services. In housing, alongside the 'right to buy' council house scheme, the Thatcher administrations repositioned the central state as a distributor of public funds and local councils as 'strategic enablers' for alternative providers. Compulsory competitive tendering was introduced for delivering new projects, and even non-profit housing associations had to compete for fixed grants on new builds and raise private finance for social housing projects. ${ }^{36}$

In healthcare, neoliberal reforms built upon earlier impulses and tools that had been introduced to control costs and assist planning. Furthering practices of oversight and priority-setting developed under Labour governments, between 1982 and 1983 Conservative administrations instituted a review of financial auditing of NHS bodies, created a host of performance indicators (to enable cross-authority comparisons on resource use), and introduced annual performance reviews of health authorities. ${ }^{37}$ As noted, parliamentary scrutiny committees provided a cross-party prompt in this direction. ${ }^{38}$ 
The first major change in policy, though one intended to support reviews and efficiency measures, was the introduction of general management into the NHS. Consensus management teams were replaced by individual managers at each level of the health service, ensuring 'responsibility drawn together in one person, at different levels of the organisation, for planning, implementation and control of performance. ${ }^{39}$ The reforms followed a six-month review of the NHS conducted by a small team of senior civil servants and business leaders, led by Roy (later Sir Roy) Griffiths, then managing director of Sainsbury's supermarkets. ${ }^{40}$ The resulting report, whilst very respectful of clinicians and the NHS, echoed public choice theorists by suggesting that it 'cannot be said too often that the National Health Service is about delivering services to people. It is not about organising systems for their own sake.' The solution to inwardly focused professionals and bureaucrats emerged from the argument that there were 'clear similarities between NHS management and business management'. Thus the NHS could be subject to the same sorts of management roles and strategies as certain forms of profit-oriented organisation: managers would be concerned with 'levels of service, quality of product, meeting budgets, cost improvement, productivity, motivating and rewarding staff, research and development, and the long-term viability of the undertaking', all of which, 'in the private sector ... would normally be carefully monitored against pre-determined standards and objectives. ${ }^{41}$ As well as undertaking 'real output measurement, against clearly stated management objectives and budgets', managers were charged with enrolling clinicians more effectively into management (and doctors were invited to become managers themselves). ${ }^{42}$ Doctors - whose decisions allegedly 'dictate[d] the use of all resources' - would help to set priorities, establish measurements of output in terms of patient care, and 'accept the management responsibility that comes with clinical freedom. ${ }^{43}$ Expressing ideas of what scholars would call 'new public management', Griffiths thus suggested that incorporating accounting and managerial techniques from 'private'-sector bodies would help reorient the NHS to efficient 'public' service. ${ }^{44}$

Following Griffiths, the government embarked on a broader remaking of the health service in line with neoliberal and new public management analyses. ${ }^{45}$ The Conservatives laid out the initial direction of travel in 1986 and 1987, with consultative and programme papers for reforms to primary healthcare. ${ }^{46}$ Here the government discussed targetbased, pay-for-performance elements of GP work, as well as strategies 
to reduce resource-wasting variations in care. ${ }^{47}$ Under the new plans, Family Practitioner Committees, previously administrative agencies, would be reconstituted as managerial bodies. Through specified performance indicators and annual reports from GPs, the committees (later renamed Family Health Services Authorities, FHSAs) could assess the quality and level of primary care provision. Furthermore, the committees would monitor variations in practice standards and care (e.g. differences in referrals) and be empowered to obtain independent professional advice to improve activity. ${ }^{48}$

These reforms were enforced, despite considerable resistance, in the 1990 GP contract. ${ }^{49}$ Complementary changes to the dynamics of the NHS were introduced by the 1989 White Paper Working for Patients and the resultant 1990 NHS and Community Care Act. ${ }^{50}$ Through these documents, the third Thatcher administration (1987-90) made alterations to the roles and funding of health authorities, hospitals, GPs, and the Department of Health, all structured by the belief that 'the Government's main task must be to set a national framework of objectives and priorities'. In turn, authorities and managers - although 'remaining accountable to the centre' - 'must then be allowed to get on with the task of managing. ${ }^{51}$ Under the new reforms, RHAs survived, but were expected to concentrate on the core managerial tasks of 'setting performance criteria', 'monitoring' and 'evaluating' performance in line with government objectives. ${ }^{52}$ They retained responsibility for numerous operational roles (such as blood transfusion services), but were expected to delegate as much responsibility to districts as possible. In turn, District Health Authorities were to delegate as many operational functions to units (hospitals) as was feasible, whilst 'ensuring that the health needs of the [ir] populations ... are met. ${ }^{53}$

Crucially, under the new arrangements District Health Authorities became purchasers of services as well as management bodies. RHAs received central funds, transferring money to districts according to assessed needs. ${ }^{54}$ District authorities subsequently 'purchased' care for their patients from hospital 'providers', which might either be directly managed (through devolved management budgets) or exist as independent trusts (initially restricted to hospitals of over 250 beds), or might operate in another district (where superior services or rates might be offered) or work in the 'private sector. ${ }^{55}$ Management of activity came either through a mixture of standard-setting and performance review (in directly provided hospitals) or from contracting (in the case of trusts or private providers). Finally, GPs were also offered the 
opportunities to become 'fundholders'. If large enough (initially having at least 11,000 registered patients), a practice could apply to receive money for a defined range of non-acute services, and then 'purchase' care directly for patients from hospitals within or without its district. ${ }^{56}$ As well as being a provider with a contract and payment for performance, it would also become a purchaser of services from secondary care institutions.

These reforms had a range of aims, not least to enable finance to flow with patients through the service and to depute operational - and thus political - accountability to non-governmental parts of the state. ${ }^{57}$ Moreover, whilst undoubtedly challenging pre-existing relationships and laying foundations for expanded private involvement in service delivery, the government's rejection of charges and insurance options meant that the reforms respected two significant principles of the NHS: central funding by taxation and universal access - a core of the supposed 'post-war consensus' - remained intact. ${ }^{58}$

Underpinning these changes, however, was an analysis consonant with contemporary neoliberal values. The introduction of stricter monitoring and accountability practices would prevent state-employed professionals from empire-building and direct their energies to meeting 'legitimate' objectives, namely providing service within available budgets. Some of this surveillance was to be undertaken at the institutional level, through reviews of practices and health authorities. However, self-review would also be performed by doctors through mandated clinical audit, with the aim of 'learning lessons', and potentially identifying and correcting costly variations in care. ${ }^{59}$ Regulated competition, now incorporated into state services, was also intended to ensure the most efficient use of state resources and maximise quality within a given capacity. The 'best' hospitals would supposedly attract funding from GPs and District Health Authorities, whilst contracting and fixed budgeting for institutions would encourage innovation and clinical efficiency. ${ }^{60}$ Finally, the intended efficiency savings would facilitate reduced taxation and lower 'inflationary spending', freeing capital for politically and economically desirable entrepreneurial activity. Notably, the state in this vision was not 'rolled back'. Instead, through the use of contracting, targets, review, and financial deputation, the central state had the potential to extend government influence further into individual units, and from here to third-sector and private providers. ${ }^{61}$ Such trends were also manifest in areas like education, with the 1988 Education Reform Act enabling individual schools to opt out of 
local authority management and funding, but only at the cost of a national curriculum, results tables, competition for places, targetsetting, and external audit. ${ }^{62}$

The reforms of the 1980s and early 1990s supported the management of medical labour in numerous ways, with legislative documents referring to clinical protocol, guidelines, and audit. Conceptually, professional management fitted neatly with the managerialism of neoliberal analyses. As with performance management and dispersed statecraft, guidelines disaggregated and codified the tasks of clinical workers, and audits subjected work and outcomes to supposedly objective measurement against pre-stated, quantified performance indicators. ${ }^{63}$ Of course, although clear conceptual cross-overs exist, there is nothing inherently neoliberal about establishing guidelines or setting and auditing targets. Socialist regimes and social democratic planning operate through similar practices. ${ }^{64}$ Nonetheless, within the neoliberal-inspired reforms of the early 1990s, the management of professional labour became tied to projects to introduce accountability practices for bureaucracies and to foster competition and market activity in public life. In terms of medicine, guidelines and auditing not only provided potential tools for judging professional work and reducing costly variations in care. They also provided mechanisms through which contracting could take place, and new providers be brought into contact with state finance. For the Department of Health, then, promoting managerial technologies in medicine could serve multiple purposes and smooth the implementation of broader projects to remake the state and its major services.

The effective implementation of government reforms relied upon co-operation from medical professionals. Politically, the response from the major professional bodies, individual doctors, and their allies within Parliament and the media was overwhelmingly critical. Many critics argued that the government sought to 'destabilise the NHS and replace it with a commercial' alternative. ${ }^{65}$ Yet opposition on structural elements of reform masked support for elements of professional management. For instance, one contributor to the BMJ suggested that 'the notion of health care being bought and sold as a market commodity' raised 'fundamental questions about the possible lack of safety nets within a restructured health service'. Nonetheless, the author continued by declaring that 'the need for greater accountability is incontestable. ${ }^{66}$ Likewise, the well-known socialist GP Julian Tudor Hart strongly criticised the government's proposals for potentially distorting good medical practice, but his critiques of 'paying for means rather than 
ends' in the GP contract did not condemn targets or incentivised work per se. ${ }^{67}$

For all the rancour, the third Thatcher administration and first Major administration (1990-92) passed legislation and imposed contracts, and thought turned to how to make the best of the new dynamics. More importantly, a cross-over of interest in the management of professional labour enabled elite professional bodies, specialist practitioners and researchers, the Department of Health, and the NHS to construct a consensus around managerial policy. Neoliberal critique may have brought government to the table, but pre-existing professional interests in management were essential to making managerial policy.

Managing diabetes and its professionals under British neoliberalism

Diabetes management was heavily influenced by the NHS reforms. Before the internal market, financial stringency was a challenge and potential opportunity for innovators. We noted in Chapter 4 how neoliberal politics interacted with the management of retinopathy. Policy support for statistical indication linked to cost reduction, moreover, provided opportunities for reformers and planners in other areas. In Manchester, for instance, pioneers of new diabetes centres - institutions dedicated to more patient-centred, multi-disciplinary care than outpatient clinics - used political drives for audit and reduced inpatient costs to their advantage. Through statistical analyses and the promise of savings, innovators garnered political support for organisational change. ${ }^{68}$ Likewise, physicians in the South-East Thames Region formed a diabetes group to facilitate the construction of a strategic plan. The group used Hospital Activity Analysis data and questionnaires to calculate the costs and activities associated with diabetes care, making the case for better forward projections and expanded staffing. Once again, they justified such activity on the grounds of reduced costs. ${ }^{69}$

Diabetes management, however, was also tied into neoliberal reforms and concerns evoked in government discussion of 'quality. ${ }^{.70}$ As noted in the Introduction, diabetes care formed a central plank in the 1990 GP contract, which had been designed to improve the management of chronic disease. The contract built on pre-existing models of GP miniclinics in diabetes and other conditions (see Chapter 2) and reinforced professional interest in systematic, managed care (Chapter 3 ). Moreover, the contract was predicated on the rationale that improved clinical practice could achieve public health aims of secondary prevention of 
long-term sequelae (Chapter 1). Unlike professionally designed schemes, however, the government contract attached financial incentives to practice-based disease management. In exchange for payment, GPs engaged in performance management relationships with FHSAs. Practitioners would develop protocols with fellow professionals, and the relevant FHSA would assess care against agreed criteria to determine financial recompense. The new arrangements, therefore, reflected the mix of projects supporting managed medicine. One the one hand, cognisant of the conflict over contemporaneous organisational change, the government left protocol and audit as the responsibility of local professionals. Doctors assumed control of developing and managing new tools, which the state encouraged through funding and providing platforms for exchange. ${ }^{71}$ On the other hand, the government tried to connect management of clinical labour with performance management structures designed to promote public health and efficiency savings. Despite potential conflict, and practitioners' anxieties that incentives might produce adverse effects, these interests formed the basis of managerial policies, and diabetes provided a key area of intervention. ${ }^{72}$

Government interest in diabetes thus partially derived from the condition's financial and humanitarian costs and its place within a broader landscape of worrisome chronic diseases. However, political focus on diabetes (and other chronic conditions) also underlined how government support for professional management gravitated towards conditions in which the infrastructure and momentum for managed practice had previously been established. As noted in earlier chapters, practitioners had experimented with local protocol for systematic care since the 1970s, whilst elite specialists and professional bodies had been producing national guidelines and undertaking audit of diabetes management for over a decade. The BDA and Royal Colleges had thus repositioned themselves as guarantors of quality structured care, and sought to produce guidance to inform local practice. Moreover, the infrastructure for professional co-operation was also already in place. The RCP and BDA, for instance, had developed close connections, auditing national provision of staffing and facilities of diabetes during the mid-1980s. ${ }^{73}$ With both agencies interested in clinical audit, the Department of Health was able to facilitate ongoing developments, for instance funding a joint BDA-Royal College working group exploring routine audit of process and outcome in the early 1990s. ${ }^{74}$ Similarly, the Department could also use funding to local centres of innovation such as Manchester - as a means to further develop managerial tools. ${ }^{75}$ 
Indeed, the link between protocol and payment in the 1990 contract undoubtedly reflected the pre-existing 'good sense' surrounding diabetes treatment and built such developments into the performancerelated system.

International trends also accelerated the creation of managerial structures, and opportunities for professional-state co-operation, in British diabetes care. As noted in Chapter 5, the St Vincent Declaration of 1989 was integral here. The Declaration set out basic quantified targets for the care and prevention of diabetes to be applied across national contexts, and resulted from a conference of leading specialists, researchers, and civil servants held under the aegis of the European regions of the International Diabetes Federation and the WHO. ${ }^{76}$ The British government signed the Declaration, which generated new national infrastructure. For instance, in 1992, the BDA and the health departments of England, Wales, Scotland, and Northern Ireland formed a joint St Vincent Taskforce to develop the auditing and care arrangements necessary to meet the proposed targets. The group comprised medical and nursing professionals, as well as healthcare purchasers, providers, and patient representatives. Some leading professionals even hoped that the Taskforce would be able to assist health authorities in their contracting duties, as purchasing bodies lacked relevant expertise. Once again, funding such work in diabetes was simpler than in other areas of care because of the infrastructure for co-operation already in place.

The management of diabetes care, however, could also provide something of a model for the management of other conditions and areas of healthcare. Such a sentiment was expressed in the second report of the Clinical Standards Advisory Group (CSAG), published in 1994. ${ }^{77}$ CSAG was a multi-disciplinary, statutory body with a rotating membership composed of nominees from the Royal Colleges and other leading professional bodies. ${ }^{78}$ It was charged with making investigations into, and providing recommendations to government on, standards of care within given subjects. Created during intense conflict over NHS reforms, it was declared by politicians, members of the profession, and policy analysts to be an attempt to broker peace between professional bodies and the government. ${ }^{79}$ Although potentially indicating the government's acceptance that the profession should set, monitor, and control its own standards, the Group's name and purpose also indicated a broad consensus over the need for more active surveillance and management of professional labour. 
The Group's second report was on diabetes care, and was researched and written by a specially chosen Diabetes Committee whose broad membership included both medical and nursing specialists as well as generalists, such as administrative officers, a nationally prominent GP, directors of public health, and leading figures within the RCP. ${ }^{80}$ The Committee followed the remit laid out in Parliament: to 'advise on standards of clinical care for people with diabetes', work which would entail 'reviews of existing statements of clinical standards, of the standards specified in NHS contracts, and of arrangements for auditing the delivery of services to contracted standards, in a representative sample of NHS districts and boards. ${ }^{, 81}$ Thus, upon creation, the Committee formed a sub-group (complete with co-opted members) to review nineteen existing international, American, and British standards, and to construct its own standards document. ${ }^{82}$ This document served as a benchmark for multi-disciplinary groups which then visited providers, purchasers, clinical teams, GPs, and 'consumer representatives' to assess provision in eleven health districts of different sizes, locations, and reputations. From these visits, the Committee produced site reports, and the parent body published the Committee's own standards document and anonymised findings, along with its recommendations and the government's response, in a final report.

The relationship between diabetes and neoliberal healthcare reforms was visible, firstly, in the very terms of reference for the Committee. The Secretary of State for Health requested analysis of standards within contracts, as well of the infrastructure in place for auditing contracts against those standards. Such demands were perhaps a reaction to broader concerns that integrated chronic disease care might have been disrupted by the 1990s reforms, and to the impenetrable 'wall' erected 'between the purchasing and provider role of the District Health Authority. ${ }^{83}$ In fact, worries about lost contracting expertise were so great that the NHS Executive in England commissioned guidance on needs assessment by one of the CSAG authors, and endorsed 'a small number of existing clinical guidelines' on diabetes in order to help purchasers draw up contracts. ${ }^{84}$ (And such decisions, once again, marked points of convergence between professional visions of selfmanagement and performance management of the health service.)

Secondly, connections between NHS reforms, diabetes, and professional management can be seen in how the exercise itself acted as a local and national review of care. The Committee produced its own standards document, and the Group's findings influenced care in at least 
some of the locales visited (see below). Finally, the report itself articulated the possible attraction of diabetes as a conduit for further managerial developments. 'This study has shown', the authors noted, 'that standards of care can be assessed against a consensus document.' 'Our approach', they went on, 'would appear to be a useful model for assessing provision of care for other diseases of public health importance. ${ }^{95}$ It was a sentiment whose importance was amplified by the mixture of specialists and generalists on the Diabetes Committee, confirming the novelty of such managerial approaches at a systemic level as well as their applicability elsewhere.

\section{Enrolling the neoliberal state and creating managerial consensus in diabetes care}

Although there were areas of cross-over between elite professional endeavours to construct non-punitive technologies of medical management and neoliberal state programmes for professional and health authority performance management, these projects were by no means in complete alignment. Moreover, despite diabetes care providing an attractive proposition for the state to pursue its managerial interests, professionals themselves were central in promoting and co-constructing managerial instruments and policy around the condition. This is notable in the histories of both the St Vincent Declaration and the CSAG report on diabetes, as well as the creation of a later NSF for diabetes in Britain.

The creation of the St Vincent Declaration was, for instance, pointedly political. The event owed much to the work of, amongst others (including British epidemiologist Hilary King), Professor Harry Keen, an internationally renowned British diabetologist. Keen felt that an international initiative to improve diabetes care - one backed by the $\mathrm{WHO}$ - would pressure national governments into more concertedly addressing the growing challenge of diabetes at a clinical and public health level. ${ }^{86}$ Furthermore, this political orientation was embodied in the form of the Declaration. Although the contents of the Declaration had been left to experts, and despite precedent in the WHO 'Health for All' initiative in 1979, there had been debate during drafting as to whether target-setting was appropriate (especially in the absence of baseline data) and what particular targets should be chosen. ${ }^{87}$ However, targets were adopted specifically because those involved feared the Declaration would be toothless without them. In the event, 
the conference adopted a mixture of quantified outcome targets (for instance, halving the rate of gangrene amputations in five years) and specific process and structure objectives, such as establishing 'monitoring and control systems using state of the art information technology for quality assurance. ${ }^{88}$ Those who worked on the Declaration and its subsequent projects felt that it probably did not affect practice at the point of individual exchanges between clinical teams and patients. Crucially, though, the Declaration did provide political tools and momentum with which bodies like the BDA could lobby government, and through which individual practitioners could encourage local doctors and NHS authorities to take up auditing and guideline practices. ${ }^{89}$ Moreover, professional lobbying was central to convincing the government to support the Declaration and to create subsidiary working groups. Interviewees who worked in relation to St Vincent, for instance, recalled civil servants' hesitancy about signing the Declaration. They noted departmental concern about 'special pleading', the idea that if the Minister for Health agreed to specific programmes for diabetes then the government would be open to similar claims for a host of conditions. Eventually, after concerted pressure, the UK did sign, creating a path for the creation of various groups for guideline and audit development schemes. $^{90}$

Post-war policy networks also secured political support for the CSAG review of diabetes standards. The review emerged, in part, from the fate of diabetes within the Major government's public health initiative, The Health of the Nation. This programme continued the work of Working for Patients in laying out a role for the state as provider of a 'strategic framework' for public health, based on managerial principles of calculated target-setting and continuous performance assessment. ${ }^{91}$ The centre would develop objectives, and, freed from the burden of delivering services day-to-day, health authorities could use contracts to achieve them. ${ }^{92}$ Initial consultation produced sixteen areas for possible intervention, including diabetes. Reflecting a growing faith in guidelines and auditing, the suggested diabetes targets included the proportion of GP practices within a FHSA area who follow protocols agreed locally between hospital clinicians and primary care staff.' 93

Despite the BDA submitting persuasive arguments for diabetes, the subsequent White Paper adopted fourteen quantified targets for five key areas: coronary heart disease and stroke, cancer, mental illness, HIV/AIDS and sexual health, and accidents. ${ }^{94}$ The Major government 
suggested that these five areas met three key criteria, being areas of considerable premature death and avoidable ill-health, in possession of known effective interventions, and amenable to target-setting and monitoring. ${ }^{95}$ Critics of the programme have suggested, by contrast, that alongside being causes of considerable NHS expenditure, the subjects chosen also contained historic trends favourable to future improvement for which the government might take credit. ${ }^{96}$ Regardless of the reasoning, diabetes was omitted from the programme. However, interviewees who had close connection with the BDA suggested that the CSAG review of diabetes services was something of a 'sop' for the omission of diabetes from The Health of the Nation. The government was aware of needing to offer a concession, and influential figures within the CSAG parent group had colleagues' interests in mind when pushing for diabetes as an area of standards investigation. ${ }^{97}$ The Group agreed, and the Diabetes Committee then pulled together leading figures in the field of diabetes management to drive the work forward. ${ }^{98}$

In this sense, rather than professionals being enrolled into state projects, specialists and elite professional bodies used the state to engage in activities that fitted their own priorities, or at least to co-operate with the state in a way that would better manage British medicine and its populations. ${ }^{99}$ As subsequent projects remained predicated upon professional expertise, participants believed that their work would improve care and empower professionals to manage their own practice, not only in ways that facilitated quality-assurance mechanisms, but also in ways with resource implications that conflicted with state concerns about costs. One site review from the CSAG report, for instance, provided the grounds for local institutions to hire a consultant diabetologist where previously one had not been in place. ${ }^{100}$ Equally, as indicated above, one interviewee involved in policy work recalled how reports like the CSAG's provided a means for the BDA to make the case for further government or health authority activity, with changes probably increasing short-term financial costs. ${ }^{101}$

As well as on professional and state co-operation, managerial policy for diabetes care also depended on the ways in which specialists moved between different bodies to produce a broad consensus on the core elements of 'quality' care. The existence of such consensus in diabetes care could be seen within the CSAG report, which suggested that 'within [the standards documents reviewed] there is a large measure of agreement on what constitutes care of acceptable quality. ${ }^{102}$ This overlap made it easier for the Diabetes Committee's sub-group to 
compile its own standards document, one which was wide-ranging in its focus but contained common elements discussed in Chapter 5, including lists of tests to be performed at medical and annual review, reflections on possible audit measures, recommendations for quantified performance indicators for patients, and discussion of the need for guidelines, registers, and recall-mechanisms. ${ }^{103}$ In part, the commonality between extant standards documents reflected the broader 'good sense' about quality diabetes care discussed in earlier chapters. Yet this good sense - and its embodiment in the documentation of various agencies - was the product of elite practitioners and academics moving between bodies that produced standards and guidelines. Members of the CSAG, for instance, were involved in shaping the St Vincent Declaration and pioneered its subsequent work on audit. They also helped produce Royal College and BDA guidelines on diabetes management, worked on NHS Executive projects, and operated on many of the guideline committees formed and funded by the Department of Health. ${ }^{104}$ Influential figures were also connected through training and research with other major figures in the field, such as Harry Keen, John Nabbarro, or Robert Tattersall. ${ }^{105}$ Specific proposals and documents, in other words, emerged out of both broader political contexts and welldefined intellectual and policy communities.

Moving between different levels of the health services, and different arenas of discussion and governance, helped these figures to align recommendations of local and regional NHS authorities, elite professional bodies, international organisations, and lay-professional and state-sponsored agencies. They thus provided sufficient agreement for managerial recommendations and infrastructures to emerge, and mediated potentially conflicting agendas. ${ }^{106}$ Using government funding and activity, certain elite specialists and professional bodies helped set national standards and, through their production of tools for management, sat at the forefront of quality regulation and governance. At the same time, through its resources and support, the government sought to use this repositioning to its own advantage, encouraging professional management in ways that furthered neoliberal drives for accountability and financial control. Undoubtedly, there were tensions and conflicts. Governments did not always support the findings of committees. They could refuse proposals that had resource implications or required direct government intervention in service provision. Equally, different aims and political realities could undermine government efforts to impose forms of performance management or contain costs. Despite these 
conflicts, though, co-operation between state agencies and elite professionals laid the foundation for future political and structural transformations and the creation of more managed medical labour.

\section{Conclusion: NSFs and the making of managerial policy}

The structure of the NHS came under further scrutiny after the mid1990s. The election of a Labour government in 1997 ended eighteen years of Conservative government and brought new analyses of the service to the fore. The Blair administrations ended fundholding and internal markets, but kept the division between purchasers and providers and enhanced primary-care influence over the service. New policy established the Primary Care Group - which brought together GPs and other primary healthcare providers in an area as budget managers - as the fulcrum of the service, and softened mechanisms of competition in favour of co-operation and long-term contracting. The new government also encouraged mixed-sector capital projects to increase hospital capacity. ${ }^{107}$

Despite such changes, both Conservative and Labour governments from the early 1990s onwards retained an emphasis on guideline, audit, and healthcare management. Structurally, the Royal Colleges, elite specialist bodies, and ad hoc statutory groups had to share their role in producing guidance and undertaking review with new state agencies that reflected the growing rhetoric around Evidence-Based Medicine. During the late 1990s, independent Evidence-Based Medicine organisations like the Cochrane Centre were joined by state-sponsored agencies such as the National Institute for Clinical Excellence (NICE), Commission for Health Improvement, and National Audit Office. ${ }^{108}$ New agencies could disrupt existing expert networks. For instance, one interviewee disliked the pressure for targets emerging from these agencies. A disagreement over the standardising drives of NICE meant that the interviewee was not involved in NICE guideline production work, despite great experience in this area ${ }^{109}$ Nonetheless, the emphasis of these agencies remained on providing guidance and undertaking review to ensure that local systems were set up to inform 'best practice. ${ }^{110}$

In terms of diabetes, the continuing political and professional support for managing medicine can be seen from the creation of an NSF for diabetes between 2001 and 2002. Once again, diabetes was at the forefront of managerial policy, with the diabetes NSF one of five initial frameworks designed to set national standards for care and 
provide strategic advice on achieving such standards. ${ }^{111}$ The diabetes framework built on a belief in managerial technologies as central to 'driv[ing] up quality and tackl[ing] variations in care', although, marking a slight break with earlier standards, it was also oriented towards patient experience and empowerment. ${ }^{112}$ The framework itself laid out twelve objectives for the NHS and discussed their implications for service providers and doctors, alongside providing a plan for how these objectives could be met. ${ }^{113}$ It also found support in new contract arrangements for GPs established under the QOF in 2004, through which complex financial incentives were developed for diabetes management (and chronic disease management more broadly) and payment was closely related to process and outcome assessment. ${ }^{114}$ As of 2018, both the QOF and the NSF are still in use, the QOF in formal contracting, the NSF indirectly, providing the basis for Diabetes UK's policy work. ${ }^{115}$

Although the NSF appeared a striking innovation, interviewees involved in its creation underlined the importance of previous political work on diabetes to its construction, praising the policy networks, conceptual frameworks, and techniques developed over preceding decades. They recalled, for instance, the work of leading figures like Harry Keen and George Alberti (then President of the RCP of London), and lobbying from agencies like Diabetes UK. ${ }^{116}$ Through slow concerted pressure and more light-touch conversations with ministers, civil servants, and the Chief Medical Officer, these actors were able to gain political momentum that was maintained by consecutive Ministers for Health. ${ }^{117}$ Figures at the heart of this work and close to the External Reference Group that compiled the standards and delivery documents recalled using the intelligence and documents accumulated through the political efforts of the previous decade. ${ }^{118}$ Indeed, the NSF itself directly made reference to 'build[ing] upon the vision of the St Vincent Declaration., ${ }^{119}$

The developments laid out in this chapter, and those proceeding it, provided the groundwork for approaches to diabetes - and British medicine more broadly - that have lasted through to the present day. Although, if focusing on contemporary infrastructure, we might suggest that the rise of managerial medicine was 'incomplete' by the mid-1990s, the principles, practices, and techniques of medicine that we have traced throughout the post-war period had nonetheless become the foundation for policy and professional practice. By the end of the 1990s, new actors were making managerial policy. None, however, questioned the idea that the structure and review of medical rhythms, decision-making, 
and outcomes were essential to guaranteeing quality care. By the start of the present century, the management of medical practice was an increasingly naturalised feature of the health services. Diabetes care, moreover, had been at the forefront of such developments.

\section{Notes}

1 N. Timmins, The Five Giants: A Biography of the Welfare State (London: Fontana Press, 1996), p. 465. Initially, becoming a self-governing trust was voluntary, but by 1997, only 5 per cent of services remained directly managed: C. Webster, The National Health Service: A Political History (Oxford: Oxford University Press, 1998), p. 198.

2 J. Lewis, 'The medical profession and the state: GPs and the GP contract in the 1960s and 1990s', Social Policy and Administration, 32:2 (1998), $132-50$.

3 On the limits to innovation: R. Klein, The New Politics of the NHS: From Creation to Reinvention, 5th edition (Oxford: Radcliffe, 2006), pp. 140-86.

4 C. Webster, The Health Services since the War, vol. I: Problems of Health Care: The National Health Service before 1957 (London: HMSO, 1988), pp. 133-96, 223; Timmins, The Five Giants, p. 381.

5 Klein, The New Politics of the NHS, pp. 35-8, 58-66.

6 T. Cutler, 'Managerialism avant la lettre? The debate on accounting in the NHS hospitals in the 1950s', in V. Berridge and K. Loughlin (eds.), Medicine, the Market, and the Mass Media: Producing Health in the Twentieth Century (London: Routledge, 2005), pp. 124-45.

7 G. Rivett, From Cradle to Grave: Fifty Years of the NHS (London: King's Fund, 1997), pp. 111-12.

8 C. Webster, The Health Services since the War, vol. 2: Government and Health Care: The British National Health Service, 1958-1979 (London: HMSO, 1996), appendix 3.10, p. 809.

9 Klein, The New Politics of the NHS, pp. 54-8.

10 G. O'Hara, From Dreams to Disillusionment: Economic and Social Planning in the 1960s (Basingstoke: Palgrave Macmillan, 2007).

11 Rivett, From Cradle to Grave, p. 181.

12 See Chapter 2. On management: S. Snow, “I've never found doctors to be a difficult bunch": doctors, managers and NHS reorganisations in Manchester and Salford, 1948-2007', Medical History, 57:1 (2013), 65-86.

13 Klein, The New Politics of the NHS, pp. 91-2.

14 R. Venugopal, 'Neoliberalism as concept', Economy and Society, 44:2 (2015), $165-87$. 
15 D. Stedman Jones, Masters of the Universe: Hayek, Friedman, and the Birth of Neoliberal Politics (Princeton: Princeton University Press, 2014), pp. 2-4.

16 M. Foucault, The Birth of Biopolitics: Lectures at the College de France, 1978-79, trans. G. Burchell, ed. M. Senellart (Basingstoke: Palgrave Macmillan, 2008), pp. 65-70; R. Pinker, 'New liberalism and the middle way', in R. Page and R. Silburn (eds.), British Social Welfare in the Twentieth Century (Basingstoke: Macmillan, 1999), pp. 80-104; E. P. Hennock, 'Poverty and social reforms', in P. Johnson (ed.), Twentieth Century Britain: Economic, Social and Cultural Change (London: Longman, 1994), pp. 79-93.

17 Stedman Jones, Masters of the Universe, pp. 2-4.

18 Ibid., pp. 37-72.

19 Ibid., pp. 47-66; J. Tomlinson, 'Planning: debate and policy in the 1940s', Twentieth Century British History, 3:2 (1992), pp. 156-8, 162-9.

20 Stedman Jones, Masters of the Universe, pp. 63-4; Foucault, The Birth of Biopolitics, p. 143.

21 Stedman Jones, Masters of the Universe, p. 76; Foucault, The Birth of Biopolitics, pp. 142-5.

22 Foucault, The Birth of Biopolitics, pp. 82-7, 117-20.

23 Ibid., pp. 133-4, 138-41, 161. Figures like Hayek also allocated states roles in maintaining stable currencies, whilst regulation also involved such things as health and safety: Stedman-Jones, Masters of the Universe, p. 67.

24 Stedman-Jones, Masters of the Universe, pp. 134-79; B. Jackson, 'The think-tank archipelago: Thatcherism and neoliberalism', in B. Jackson and R. Saunders (eds.), Making Thatcher's Britain (Cambridge: Cambridge University Press, 2012), pp. 43-61; N. Rollings, 'Cracks in the post-war Keynesian settlement? The role of organised business in Britain in the rise of neoliberalism before Margaret Thatcher', Twentieth Century British History, 24:4 (2013), 637-59.

25 Stedman-Jones, Masters of the Universe, pp. 100-3.

26 Foucault, The Birth of Biopolitics, pp. 239-316.

27 Stedman-Jones, Masters of the Universe, pp. 126-33.

28 For earlier Conservative interest: C. Muller, 'The Institute of Economic Affairs: undermining the post-war consensus', Contemporary British History, 10:1 (1996), 88-110.

29 See Chapter 4; C. Hay, 'Chronicles of a death foretold: the Winter of Discontent and the construction of the crisis of British Keynesianism', Parliamentary Affairs, 63:3 (2010), 446-70.

30 R. Lowe, The Welfare State in Britain since 1945, 3rd edition (Basingstoke: Palgrave Macmillan, 2005), pp. 29-32; A. Gamble, The Free Economy and the Strong State: The Politics of Thatcherism, 2nd edition (Basingstoke: Macmillan, 1994), pp. 34-68. 
31 P. Pierson, Dismantling the Welfare State? Thatcher, Reagan and the Politics of Retrenchment (Cambridge: Cambridge University Press, 1994).

32 Webster, The National Health Service, pp. 154-5; M. Gorsky, "Searching for the people in charge": appraising the 1983 Griffiths NHS Management Inquiry', Medical History, 57:1 (2013), 96.

33 Although it does not refer to 'neoliberalism', see discussion of principles, opportunism, and ministerial influence in Klein, The New Politics of the NHS, pp. 146-52.

34 J. Bradshaw, 'Social security', in D. Marsh and R. A. W. Rhodes (eds.), Implementing Thatcherite Policies: Audit of an Era (Buckingham: Open University Press, 1992), pp. 81-99; D. Marsh, 'Industrial relations', in Rhodes and Marsh (eds.), Implementing Thatcherite Policies, pp. 32-49; P. Addison, No Turning Back: The Peacetime Revolutions of Post-War Britain (Oxford: Oxford University Press, 2010), pp. 275-314.

35 M. Moran, 'The regulatory state', Parliamentary Affairs, 54 (2001), 19-34; D. Marsh, 'Privatization under Mrs Thatcher: a review of the literature'. Public Administration, 69 (1991), 459-80; A. Gamble, 'Privatization, Thatcherism, and the British state', Journal of Law and Society, 16:1 (1989), $1-20$.

36 P. Kemp, 'Housing', in Rhodes and Marsh (eds.), Implementing Thatcherite Policies, pp. 65-80; I. Kirkpatrick, S. Ackroyd, and R. Walker, The New Managerialism and Public Service Professions: Change in Health, Social Services and Housing (Basingstoke: Palgrave Macmillan, 2005), pp. 135-7.

37 Klein, The New Politics of the NHS, pp. 115-16; Webster, The National Health Service, pp. 165-7. Scholars have criticised these attempts to establish performance indicators as adding little to efficiency management and excluding meaningful data relating to clinical performance: Rivett, From Cradle to Grave, p. 334.

38 S. Harrison, National Health Service Management in the 1980s (Aldershot: Avebury, 1994).

39 E. R. Griffiths to N. Fowler, 'NHS Management Inquiry', 23 October 1983, reproduced in ibid., pp. 158-77, quote at p. 166.

40 Gorsky, “"Searching for the people in charge”', pp. 87-107.

41 Griffiths, 'NHS Management Inquiry', p. 165.

42 Ibid., p. 167.

43 Ibid., p. 172.

44 Although 'private' and 'public' are colloquially used to designate profitoriented business and tax-funded state agencies respectively, the terms have malleable histories. Most importantly, techniques such as budget and programme review were common in state agencies before the 1980s. Other practices, later imported from businesses, were not necessarily common, and the view of the 'private' sector from within government was highly specific: J. Clarke and J. Newman, The Managerial State: Power, 
Politics and Ideology in the Remaking of Social Welfare (London: Sage, $1997)$, pp. 27-9, 56. On the internal consistency of new public management: Kirkpatrick et al., The New Managerialism, pp. 64-5.

45 For responses to Griffiths: Gorksy, "Searching for the people in charge”, pp. 101-5.

46 Secretaries of State for Social Services, Wales, Northern Ireland, and Scotland, Primary Health Care: An Agenda for Discussion, Cmnd 9778 (London: HMSO, 1986); Secretaries of State for Social Services, Wales, Northern Ireland, and Scotland, Promoting Better Health: The Government's Programme for Improving Primary Health Care, Cm 249 (London: HMSO, 1987).

47 Secretaries of State for Social Services, Promoting Better Health, pp. 13-16, 23.

48 Ibid., pp. 23-4, 53-4.

49 Klein, The New Politics of the NHS, pp. 158-61; Lewis, The medical profession and the state', pp. 139-44.

50 Secretaries of State for Social Services, Wales, Northern Ireland, and Scotland, Working for Patients, Cm 555 (London: HMSO, 1989); National Health Service and Community Care Act 1990, c. 19.

51 Secretaries of State for Social Services, Working for Patients, p. 12.

52 Ibid., p. 13.

53 Ibid., p. 14.

54 Ibid., pp. 30-3.

55 Ibid., pp. 33-5; on the criteria and process of acquiring trust status: pp. $22-9$.

56 Ibid., pp. 49-53.

57 Klein, The New Politics of the NHS, pp. 150-1. See also Clarke and Newman, The Managerial State, pp. 29-33.

58 Klein, The New Politics of the NHS, pp. 146-58.

59 Secretaries of State for Social Services, Working for Patients, pp. 39-42, $55-60$.

60 Ibid., pp. 16, 20-4, 30-7.

61 Clarke and Newman, The Managerial State, pp. 29-33.

62 G. Whitty, 'The New Right and the national curriculum: state control or market forces', in M. Flude and M. Hammer (eds.), The Education Reform Act, 1988: Its Origins and Implications (London: Falmer Press, 1990), pp. 21-36.

63 Kirkpatrick et al., The New Managerialism, p. 59.

64 A. B. Kipnis, 'Audit cultures: neoliberal governmentality, socialist legacy, or technologies of governing?', American Ethnologist, 35:2 (2008), 275-89.

65 Hansard, HC, vol. 152, cols. 1027 and cols. 1037, 11 May 1989; Klein, The New Politics of the NHS, pp. 152-61; Timmins, The Five Giants, pp. 465-71 
66 J. Bain, 'NHS review', BMJ, 298:6675 (1989), 746.

$67 \mathrm{~J}$. T. Hart, 'Coronary heart disease: preventable but not prevented?', British Journal of General Practice, 40:340 (1990), 441-2, esp. p. 441.

$68 \mathrm{H}$. Valier and R. Bivins, 'Organization, ethnicity and the British National Health Service', in J. Stanton (ed.), Innovations in Health and Medicine: Diffusion and Resistance in the Twentieth Century (London: Routledge, 2002), pp. 46-7.

69 W. D. Alexander and South East Thames Diabetes Physicians Group, 'Diabetes care in a UK health region: activity, facilities, and costs', Diabetic Medicine, 5:6 (1988), 577-81.

70 On the politics of quality: I. Kirkpatrick and M. M. Lucio (eds.), The Politics of Quality in the Public Sector: The Management of Change (London: Routledge, 1995).

71 P. Day, R. Klein, and F. Miller, A Comparative US-UK Study of Guidelines (London: Nuffield Trust, 1998), pp. 22-7.

72 D. J. Paynton, 'The NHS bill, the GP contract, and diabetic care', Diabetic Medicine, 8:3 (1991), 286.

73 RCP of London and BDA, The Provision of Medical Care for Adult Diabetic Patients in the United Kingdom (London: BDA, 1984).

74 D. R. R. Williams, P. D. Home, and Members of a Working Group of the $\mathrm{RCP}$ and BDA, 'A proposal for continuing audit of diabetes services', Diabetic Medicine, 9:8 (1992), 759-64.

75 I. J. Bennett, C. Lambert, G. Hinds, and C. Kirton, 'Emerging standards for diabetes care from a city-wide primary care audit', Diabetic Medicine, 11:5 (1994), 489-92.

76 A-M. Felton and M. S. Hall, 'Diabetes - from St Vincent to Glasgow. Have we progressed in 20 years?', British Journal of Diabetes and Vascular Disease, 9:4 (2009), 142.

77 CSAG, Standards of Clinical Care for People with Diabetes (London: HMSO, 1994).

78 The parameters for the body - including composition - were laid out in a Statutory Instrument: The Clinical Standards Advisory Group Regulations 1991, No. 578, available at: https://www.legislation.gov.uk/ uksi/1991/578/introduction/made (accessed April 2018).

79 J. Warden, 'Peace in our time', BMJ, 300:6736 (1990), 1359; Klein, The New Politics of the NHS, p. 161.

80 CSAG, Standards of Clinical Care for People with Diabetes, appendix 3, p. 34.

81 Ibid., p. 1.

82 Ibid., pp. 17-18, 34, appendix 1 and appendix 3.

83 Paynton, 'The NHS bill, the GP contract, and diabetic care'.

84 CSAG, Standards of Clinical Care, pp. 35-7, 36.

85 Ibid., p. 2. 
86 Interview with Professor Whittaker conducted by the author; interview with Professor Davies conducted by the author. Professor Whittaker is a retired consultant diabetologist who worked within major centres of diabetes care and research between the 1970s and 2000s. Professor Davies is a retired epidemiologist and health authority member who worked within major centres of diabetes care and research between the 1970s and 2000 s, as well as undertaking government advisory and university administration work.

87 Interview with Professor Davies.

88 Ibid. For the declaration: G. E. Reiber and H. King, Guidelines for the Development of a National Programme for Diabetes Mellitus' (Geneva: WHO, 1991), annex 5, p. 62.

89 Interview with Professor Davies; interview with Professor Whittaker; interview with B. Potts conducted by the author. Potts presently works in Diabetes UK, and previously worked within an audit advisory group during the 1990s. K. Piwernetz, P. D. Home, O. Snorgaard, M. Antsiferov, K. Staehr-Johansen, and M. Krans for the DiabCare Monitoring Group of the St Vincent's Declaration Steering Committee, 'Monitoring the targets of the St Vincent Declaration and the implementation of the quality management in diabetes care: the DiabCare initiative', Diabetic Medicine, 10:4 (1993), 371-7.

90 Interview with Professor Davies.

91 Department of Health, The Health of the Nation: A Consultative Document for Health in England, Cm 1523 (London: HMSO, 1991), p. iv.

92 Ibid., pp. iii-iv.

93 Ibid., pp. 84-5.

94 Department of Health, The Health of the Nation: A Strategy for Health in England, Cm 1986 (London: HMSO, 1992); WLA, MSS (10522), BDA, 'The Health of the Nation: response from the British Diabetic Association', October 1991.

95 Department of Health, The Health of the Nation: A Strategy for Health in England, pp. 15-20.

96 Klein, The New Politics of the NHS, p. 169; interview with Professor Whittaker.

97 Interview with Professor Davies.

98 Ibid.; interview with Professor Whittaker.

99 S. Pickard, 'The role of governmentality in the establishment, maintenance, and demise of professional jurisdictions: the case of geriatric medicine', Sociology of Health and Illness, 32:7 (2010), 1072-86. But interaction was a two-way street, and subject to government interests: S. Sheard, 'Quacks and clerks: historical and contemporary perspectives on the structure and function of the British medical civil service', Social Policy \& Administration, 44:2 (2010), 193-207. 
100 Interview with Professor Davies.

101 Interview with B. Potts.

102 CSAG, Standards of Clinical Care, p. 17.

103 Ibid., pp. 18-29.

104 Ibid., p. 35. Philip Home, Rhys Williams, and Colin Waine, for instance, had all worked either on St Vincent's projects, on Royal College guideline production, or in other departmental capacities, as well as on the CSAG: cf. ibid., p. 34: ibid., pp. 36-7; Piwernetz et al., 'Monitoring the targets of the St Vincent Declaration'; C. Waine, Why Not Care for your Diabetic Patients?, 2nd edition (London: RCGP, 1988).

105 Interview with Professor Davies; interview with Professor Whittaker.

106 On the importance of individuals moving across arenas of discussion and action to stabilise projects: B. Latour, The Pasteurization of France, trans. A. Sheridan and J. Law (Cambridge, MA: Harvard University Press, 1993).

107 Klein, The New Politics of the NHS, pp. 192-8.

108 S. Harrison and B. Wood, 'Scientific-bureaucratic medicine and UK health policy', Policy Studies Review, 17:4 (2000), 25-42.

109 Interview with Professor Whittaker.

110 Klein, The New Politics of the NHS, pp. 197-9.

111 G. Chapman, S. Adam, and D. Stockford, 'National Service Frameworks: promoting the public health', Journal of Epidemiology and Community Health, 55:6 (2001), 373-4.

112 Department of Health, National Service Framework for Diabetes: Standards (London: Department of Health, 2001), p. 11.

113 Ibid.; Department of Health, National Service Framework for Diabetes: Delivery Strategy (London: Department of Health, 2002).

114 A. Dixon, A. Khachatryan, A. Wallace, S. Peckham, T. Boyce, and S. Gillam, Impact of Quality and Outcomes Framework on Health Inequalities (London: King's Fund, 2011).

115 Interview with B. Potts.

116 Interview with Professor Davies; interview with B. Potts.

117 Interview with B. Potts.

118 Ibid.; interview with Professor Davies.

119 Department of Health, National Service Framework for Diabetes: Standards, p. 11. 